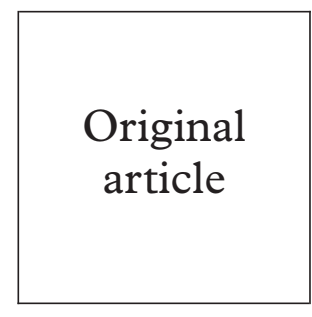

Original article

Naval Medical Center San Diego, CA, USA M R Wallace

University of California at San Diego, CA, USA

J A Nelson

J A McCutchan

$\mathrm{T}$ Wolfson

I Grant

San Diego VA Healthcare System, CA, USA

I Grant

Correspondence to: Clinical Investigation Department, Naval Medical Center San Diego, 34800 Bob Wilson Drive, Suite 5 , San Diego, CA 92134-1005, USA

mrwallace@

nmcsd.med.navy.mil

Accepted for publication 8 March 2001

\title{
Symptomatic HIV seroconverting illness is associated with more rapid neurological impairment
}

\author{
M R Wallace, J A Nelson, J A McCutchan, T Wolfson, I Grant, for the HNRC Group
}

Objectives: To establish whether symptomatic seroconverting illness in HIV infected people is associated with more rapid development of neurological impairment.

Methods: 166 HIV infected subjects with a known date of HIV infection enrolled in a longitudinal study of neurocognitive function were stratified by whether or not they had experienced a symptomatic serconverting illness.

Results: 29 of $166(17.5 \%)$ dated HIV seroconverters had a history of symptomatic seroconverting illness. Though baseline neurocognitive function was similar, subjects with a symptomatic seroconverting illness developed clinical neurocognitive impairment significantly more rapidly than their asymptomatic counterparts in a survival analysis model (636 $v 1075$ days till impaired).

Conclusion: Symptomatic seroconverting illness predisposes to more rapid neurocognitive impairment.

(Sex Transm Inf 2001;77:199-201)

Keywords: HIV; seroconverting illness; neurocognitive impairment

\section{Introduction}

Symptomatic acute retroviral infection occurs in $10-90 \%{ }^{1-5}$ of patients with primary HIV infection. This illness is often ascribed to a "viral infection" and not recognised as a possible HIV seroconverting illness. ${ }^{6-8}$ Multiple studies have reported that a symptomatic initial infection is associated with a more rapidly progressive HIV disease. ${ }^{3}{ }^{8-13}$

Neurobehavioural complications occur commonly in HIV, and range from asymptomatic mild neurocognitive disturbances such as difficulties in attention and memory to frank dementia. ${ }^{14}$ Because HIV can be detected in cerebrospinal fluid (CSF) early in the course of infection, and since seroconverting illness is accompanied by neurological symptoms, we speculated that symptomatic HIV seroconverting illness might also be associated with a greater likelihood of developing neurocognitive impairment. To explore this issue we examined the hazard of becoming neurocognitively impaired as a function of experiencing seroconverting illness in a group of men for whom approximate dates of seroconversion were available.

\section{Methods \\ PATIENTS}

The HIV Neurobehavioral Research Center (HNRC), a collaboration of the University of California at San Diego, the San Diego Veterans Affairs Medical Center, and the Naval Medical of San Diego, has evaluated the neurobehavioural effects of HIV infection in a cohort of HIV infected subjects since 1989. A detailed description of the cohort has been published previously. ${ }^{15}$ The relevant research committees at the three hospitals approved the research effort, and all subjects provided written informed consent. We selected a subset of $166 \mathrm{HIV}$ infected US military personnel who were enrolled in HNRC programme; these 166 subjects represent the dated military seroconverters with 2-6 years of complete follow up. We defined a dated seroconverter as a subject with a documented negative HIV ELISA within 3 years of their first positive HIV ELISA/western blot. The military health records of the dated seroconverters were then reviewed in detail for unexplained febrile illnesses during the period of documented HIV seroconversion. We defined a symptomatic seroconverting illness as an otherwise unexplained febrile episode lasting at least 3 days with one or more of the following symptomspharyngitis, adenopathy, diffuse rash, myalgias, headache, oral lesions, or malaise. There were 164 men and two women in the group, and their mean age was 28 years. The mean educational level was 12.9 years.

MEDICAL AND NEUROCOGNITIVE (NC)

ASSESSMENT

Participants had had a comprehensive medical neuropsychological, psychiatric, and neurological examinations at study entry and at least annually thereafter. The annual NC evaluation consisted of an extended Halsted-Reitan battery with extra tests of attention, learning, memory, and language skills and the Wechsler Adult Intelligence Scale-Revised. ${ }^{15}$ Before analysis, all raw test scores were converted to age, education, and sex corrected standardised scores using published procedures based on data from large normative subject samples. ${ }^{15-17}$ Using these demographically adjusted scores, clinical ratings of NC functioning in eight major ability areas (verbal, abstraction, psychomotor, attention/speed of information processing, learning, memory, motor, and sensory) 


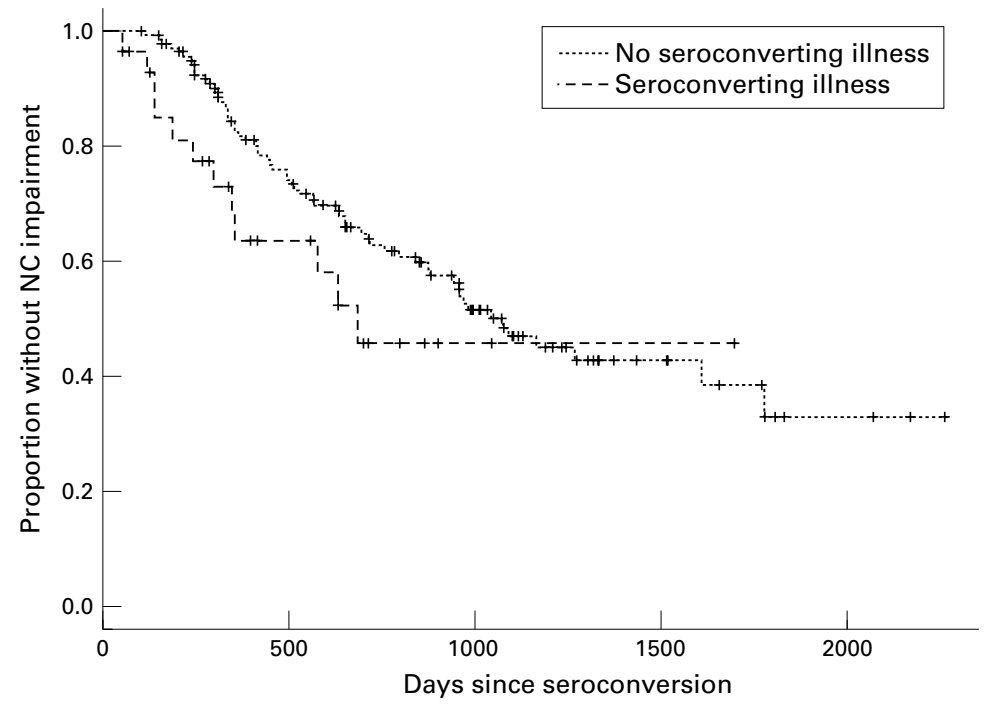

Figure 1 Survival plot. patients with a symptomatic seroconverting illness developed clinical neurocognitive impairment more rapidly than their asymptomatic counterparts in a survival analysis model (636 $v 1075$ days till global functioning within the impaired range, $\mathrm{p}=0.04$ ) (fig 1 ). Antiretroviral drug use was more common in the symptomatic seroconverting illness group, but this difference was not significant $(66 \%$ v $47 \%$, $\mathrm{p}=0.1$ ).

\section{Discussion}

The seroconverting illnesses observed in our patients did not differ substantially from those in earlier reports. ${ }^{23}$ Most of the 29 patients who were seen by healthcare professionals during their seroconverting illness were felt to have suffered a "prolonged viral infection," but in no case was the correct viral infection (acute HIV) diagnosed. This is not surprising given the low HIV seroconversion rates $(0.02 \% /$ year $)$ among US military personnel and the much more common entities which resemble symptomatic primary HIV infection (Epstein-Barr virus, cytomegalovirus, toxoplasmosis, rubella, influenza, adenovirus, etc). Even studies designed specifically for early detection of seroconverting HIV disease have often missed typical cases. $^{6}$

The frequency of symptomatic primary HIV disease in our cohort $(17.5 \%)$ was similar to that observed in studies by Dorrucci et $a l^{3}$ $(10 \%)$, Veugelers et $a l,{ }^{4}(13.8 \%)$ and Sinicco et $a \bar{P}(17 \%)$, but much less than the $50-90 \%$ rates found by other investigators. ${ }^{129}$ What might account for these widely disparate rates of acute retroviral syndrome is unclear, but may be related to the threshold used to define a significant illness. We interviewed all newly documented HIV-1 seroconverters and reviewed their military health records to see if they had visited military healthcare providers with unexplained, prolonged febrile illnesses matching the usual description of the acute HIV seroconverting illness. It is probable that our methods overlooked less severe or atypical cases.

Our data support previous reports that have shown that symptomatic seroconversion is a major risk factor for more rapid CD4 depletion and/or AIDS. ${ }^{3-5-13}$ The poorer prognosis of patients with severe seroconverting illness is probably related to higher initial HIV loads and resultant rapid CD4 depletion ${ }^{18}$; whether such a relation will continue with the advent of highly active antiretroviral therapy (HAART) is unclear.

The new finding of our study is that symptomatic HIV seroconverting illness appears to predispose to more rapid neurocognitive deterioration. One study has found that neurological signs and symptoms occurring as part of an HIV seroconverting illness predispose to more rapid immunological deterioration, ${ }^{19}$ but this is distinct from our observation as only one of our 29 subjects had any neurological findings at the time of seroconverting illness.

HIV therapy using zidovudine appears to diminish the likelihood of severe neurocognitive sequelae ${ }^{20}$; whether the use of HAART will 
additionally benefit HIV infected people at risk remains unknown. The role of antiretroviral therapy in acute HIV infection is also unclear, but data from two placebo controlled trials suggest that zidovudine therapy during primary HIV infection improves the clinical course and CD4 counts. ${ }^{21}{ }^{22}$ Whether treatment of symptomatic, primary HIV infection could modify the predisposition towards neurocognitive deficits is unknown, but given our increasing knowledge of the dynamics of early HIV infection, such intervention appears increasingly reasonable. Primary HIV infection may soon properly be regarded as a medical emergency, ${ }^{23}$ carrying with it the risk of more rapid immunological and neurological impairment, but also perhaps providing an opportunity to initiate aggressive therapy and modify the course of illness.

The views expressed in this article are those of the authors and do not reflect the official policy or position of the Department of the Navy, Department of Defense, or the United States the Navy, Dep

The Chief, Bureau of Medicine and Surgery, Navy Department, Washington, DC, Clinical Investigation Program, sponsored this report NO S89-030 as required by NSHS BETHINST 6000.41A. Supported by NIMH Award MH 45294 (HIV Neurobehavioral Research Center)

The authors thank Sylvia Romero for help in preparing the manuscript.

1 Tindall B, Cooper DA. Primary HIV infection: host responses and intervention strategies. AIDS 1991;5:1-14. 2 Clark SJ, Shaw GM. The acute retroviral syndrome and the pathogenesis of HIV-1 infection. Sem Immunol 1993:149 55.

3 Dorrucci M, Rezza G, Vlahov D, et al. Clinical characteristics and prognostic value of acute retroviral syndrome among injecting drug users. AIDS 1995;9:597-604.

4 Veugelers PJ, Kaldor JM, Strathdee SA, et al. Incidence and prognostic significance of symptomatic primary human immunodeficiency virus type infection in homosexual men. F Infect Dis 1997;176:112-17.

5 Sinicco A, Fora R, Sciandra M, et al. Risk of developing AIDS after primary acute HIV-1 infection. F Acquir Immune Defic Syndr 1993;6:575-81.

6 Schacker T, Collier AC, Hughes J, et al. Clinical and epidemiologic features of primary HIV infection. Ann Intern Med 1996;125:257-64.
7 Gaines H, Sydow MV, Pehrson PO. Clinical picture of priGaines H, Sydow MV, Pehrson PO. Clinical picture of primary HIV infection presentin

8 Kinloch-deLoes S, Saussure P, Saurat Hilaire-J, et al. Symptomatic primary infection due to human immunodeficiency virus type 1: review of 31 cases. Clin Infect Dis 1993;17:59-65.

9 Lindbach S, Brostrom C, Karlsson A, et al. Does symptomatic primary HIV-1 infection accelerate progres$200 \times 10^{6} / 1$, AIDS and death from AIDS? BMF 1994;309: 1535-7.

10 Pedersen C, Lindhardt BO, Jensen BL, et al. Clinical course of primary HIV infection: consequences for subsequent course of infection. BM7 1989;299:154-7.

11 Keet I, Krijnen P, Koot M, et al. Predictors of rapid progresKeet I, Krijnen P, Koot M, et al. Predictors of rapid progres-
sion to AIDS in HIV-1 seroconverters. AIDS 1993;7:51-7.

12 Schechter MT, Craib JP, Le TN, et al. Susceptibility to AIDS progression appears early in HIV infeciton. AIDS 1990;4:185-90.

13 Henrard DR, Daar E, Farzadegan H, et al. Virologic and immunologic characterization of symptomatic and asymptomatic primary HIV-1 infection. F Acquir Immune Defic Syndr Hum Retrovirol 1995:305-10.

14 McArthur JC, Grant I. HIV neurocognitive disorders In: Gendelman HE, Lipton SA, Epstein L, Swindells S, eds. Neurological and neuropsychiatric manifestations of HIV-1 infection. New York: Chapman and Hall, 1998.

15 Heaton RK, Grant I, Butters N, et al. The HNRC 500 - neuropsychology of HIV infection at different stages. f Int Neuropsychol Soc 1995;1:231-51.

16 Heaton RK, Grant I, Matthews CG. Comprehensive norms for an expanded Halstead-Reitan battery: a supplement for the WAIS-R. Odessa, FL: Psychological Assessment Resources, Inc, 1992.

17 Heaton RK. Comprehensive norms for an expanded HalsteadReitan battery: a supplement for the WAIS-R. Odessa, FL: Psychological Assessment Resources, Inc, 1991.

18 Vanhems P, Lambert J, Cooper DA, et al. Severity and prognosis of acute human immunodeficiency virus type 1 illness: a dose-response relationship. Clin Infect Dis 1998;26:323-9.

19 Boufassa F, Bachmeyer C, Carre N, et al. Influence of neurologic manifestations of primary human immunodeficiency virus infection on disease progression. F Infect Dis $1995 \cdot 171: 1190-5$.

20 Bell JE, Donaldson YK, Lowrie S, et al. Influence of risk group and zidovudine therapy on the development of HIV encephalitis and cognitive impairment in AIDS patients. AIDS 1996;10:493-9.

21 Kinloch-de Loes S, Hirschel BJ, Hoen B. A controlled trial of zidovudine in primary human immunodeficiency virus infection. N Engl F Med 1995;333:408-13.

22 Niu MT, Bethe J, Holodniy M. Zidovudine treatment in patients with primary (acute) human immunodeficiency virus type 1 infection: a randomized, double-blind, placebo-controlled trial. $\mathcal{F}$ Infect Dis 1998;178:80-91.

23 Jolles S, Kinloch de Loes S, Johnson MA, et al. Primary HIV-1 infection: a new medical emergency? BMF 1996; 312:1243-4. 